\title{
A FIGURA HUMANA FRAGMENTADA NA PINTURA CONTEMPORÂNEA BRASILEIRA
}

\author{
Regilene Aparecida Sarzi Ribeiro ${ }^{1}$
}

\section{Resumo}

Uma análise crítica e comparativa de pinturas contemporâneas cujo tema é a Figura Humana representada por partes do corpo humano - pernas, braços, torsos e outras compreendidas como Fragmento e Pormenor é o assunto desta pesquisa. O aporte teórico baseia-se nos conceitos de Fragmento e Pormenor do teórico italiano Omar Calabrese (1988). O recorte temporal compreende algumas produções pictóricas do Neoclassicismo e Realismo - séc. XIX - até o Cubismo e a Pop Arte - séc. XX. São analisados seus aspectos estéticos, contextualizando-as historicamente, a fim de relacioná-las com a teoria de Calabrese, discutir sua importância no cenário artístico nacional contemporâneo e sua posição na História da Arte e da Pintura.

Palavras-Chave: história da arte, pintura, figura humana, fragmento.

\begin{abstract}
:
One critique analysis and comparative of contemporary paintings whose motive is the Human Figure represented by parts of human body - legs, arms, torsos and others comprehend when Fragment and Detail is the topic of this research. The theoretical reference if base on the ideas of Fragment and Detail of the italian theoric Omar Calabrese (198). The temporal cut comprehend some pictorial productions of the Neoclassic and Realism - 19th century - until Cubism and Pop Art - 20th century. They're analyse in yours esthetics aspects, your historic context, for with regard to the Calabrese's theory, discuss your importance on the artistic national contemporary scenery and your position on the Art History and Paiting.
\end{abstract}

Key Words: art history, painting, human figure, fragment.

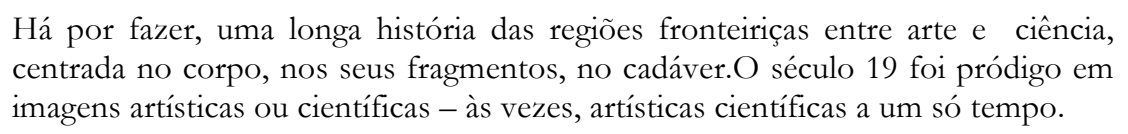
centrada no corpo, nos seus fragmentos, no cadáver.O século 19 foi pródigo em
imagens artísticas ou científicas - às vezes, artísticas científicas a um só tempo.

(Jorge Coli)

Este trabalho é resultado da análise dos dados iniciais - levantamento bibliográfico e fundamentação teórica - da Pesquisa apresentada ao Programa de Mestrado em Artes Visuais do Instituto de Artes da UNESP, campus de São Paulo e que está sendo realizada sob a orientação do Prof. Dr. José Leonardo do Nascimento.

Portanto, se refere ao Percurso Histórico do Tema da Pesquisa na História da Arte Ocidental e uma Análise Estética quanto ao tratamento da Figura Humana, que será realizado através da analise crítica e comparativa de um conjunto de obras pictóricas, cujo tema é a Figura Humana Fragmentada, a partir do século XIX - Neoclassicismo e Realismo até a chegada das Vanguardas Artísticas - do Cubismo a Pop Arte, no século XX.

O próximo passo da Pesquisa será relacionar a Pintura Contemporânea Brasileira com o Percurso Histórico que aqui apresentamos, contextualizar tal produção nacional e

\footnotetext{
${ }^{1}$ Mestrado, Programa de Pós-Graduação em Artes - Instituto de Artes - UNESP - São Paulo.
} 
discutir seu papel no cenário artístico nacional, bem como sua importância para a História da Arte e da Pintura Contemporânea Brasileira.

Entre os brasileiros encontramos o tema da figura humana na obra de artistas como Iberê Camargo (1914-1994), Carlos Vergara (1941), Luís Paulo Baravelli (1942), Leonilson (1957-1993), Rosângela Rennó (1962), Alex Flemming (1954) e Adriana Varejão (1964), entre outros.

Do século XVIII para o XIX, surge uma nova configuração do olhar humano sobre si mesmo, que vai alterar sensivelmente o sistema de representação da figura humana: que antes era um sistema representativo, pautado na tradição clássica, na inspiração religiosa e no respeito pelo intacto - pelo corpo belo e coeso; para uma frieza e racionalidade técnicas que paulatinamente expõe o corpo e sua fragilidade, suas deformações e torna essa figura humana representada mais próxima do real, no sentido de aproximação com a realidade e não mais idealizada, como sempre fora pela cultura clássica.

Esse foco sobre si mesmo, desloca o olhar do homem do Divino para o seu próprio ser, para o seu corpo real. Por conseguinte, o corpo é agora colocado em evidência e à disposição da arte e da ciência:

De imagem divina até o Neoclassicismo o Corpo passa a ser exposto no século 19 em toda a sua fragilidade e a se constituir numa poética do fragmento contra as certezas científicas e a tirania da perfeição (Coli, 2002, p.5).

Tal comportamento, marcado pela emancipação cultural do corpo que durante séculos foi representado como símbolo da integridade humana e espelho da beleza e da divindade, sofre uma divisão entre sujeito e objeto que passa agora a ser suporte do eu, mas também de outros. Esse corpo é encarnação e representação ao mesmo tempo - carne e imagem da carne.

Essa nova relação do homem com o seu corpo se estabelece na medida em que, segundo Villaça e Góes (2001),

\footnotetext{
a instabilidade ou impossibilidade da representação corporal surge como efeito de fatores como o abandono da concepção divina dos corpos, o crescimento do materialismo com as teorias do homem-máquina, base de uma relação mais técnica do que ética com o corpo e a crise do humanismo depois das grandes guerras (Villaça e Góes, 2001, p.132).
}

\section{Um Percurso Histórico - da totalidade à fragmentação da figura humana na pintura contemporânea.}

Movido pelo ideal do Humanismo, que pode ser compreendido como a valorização do homem e da natureza em oposição ao divino; ao sobrenatural e marca o grande movimento cultural em direção ao indivíduo e à pesquisa do real, o Renascimento movimento artístico que perdurou entre os séculos XV e XVI - foi muito mais que o simples reviver da antiga cultura greco-romana.

Em "A lição de Anatomia do Doutor Tulp" (1632), de Rembrandt (1606-1669), o artista utiliza recursos pictóricos e através do uso da gradação de meios tons, das penumbras que envolvem os personagens da cena e uma intensa luz no corpo do cadáver, que está sendo dissecado, cria um clima de descoberta e curiosidade pelo tema e estabelece uma relação significativa com a pintura de figura humana da época.

Para Silva (2001) essa obra de Rembrandt, é

um exemplo clássico do início de um novo período no que se refere à concepção de corpo e que é impensável em épocas anteriores, porém o desenvolvimento da 
ciência tradicional traz uma valorização do conhecimento inexistente até então (Silva, 2001, p.17).

No Neoclassicismo (1780/1830) o projeto de "beleza", que é proposto como instrumento de conhecimento universal e visava abranger todos os ramos do saber humano, buscou melhorar o mundo através do retorno à razão e de um agudo senso de moralidade.

Essa forma de racionalização, que apresenta suas raízes nas perspectivas de Descartes e Newton, se estende a vários setores da sociedade, inclusive à Arte." (Silva, 2001, p.18).

A representação do corpo humano ainda significava o centro e o apogeu da arte neoclássica e o respeito pelo entendimento das formas humanas era tanto, que o aprendizado neoclássico previa primeiro a pintura dos modelos nus, para depois representá-los vestidos. Para Coli (2002), essa postura "coincide com o respeito religioso pela intacta coesão do corpo", mas "agora, pela visão científica, as partes, organiżadas e em função, produz̨em o todo" (Coli, 2002, p.5).

A revolução iluminista, marcada pela postura científica e metódica, vinculou a desmontagem do corpo em partes, à compreensão do todo. No final do século XVIII, enquanto a arte neoclássica estabelecia o estudo das partes do corpo humano, com a finalidade de representar melhor o conjunto perfeito, surgia a Guilhotina, instrumento que garantia a todos os criminosos o mesmo tipo de morte (já que antes os plebeus eram enforcados e os aristocratas, decapitados) e que colocou o cadáver humano em evidência, junto com as guerras modernas do período napoleônico onde milhares de pessoas foram mortos e aleijados.

As características da representação da figura humana, com o Romantismo e com o Realismo, que surgem na Europa em meados do século XIX, são modificadas pela dramaticidade e sensibilidade dos temas e revelam aspectos que se contrapõem: como a beleza dos corpos humanos em oposição à dor e ao sofrimento que essa mesma condição humana é capaz de proporcionar aos seres humanos.

É um realismo que de forma alguma é uma imitação da natureza e sim uma recusa moral da concepção clássico-cristã da arte como catarse, como afirma Argan (1992) a respeito das características do realismo do pintor francês Théodore Géricault (1791-1824). Para Argan, "o 'realismo' é a derrota do ideal, a inutilidade e a negatividade da história", por isso que Géricault busca captar num mesmo corpo a grandeza e a decadência, o belo e o feio, a nobreza e a depravação, a vida em sua contrariedade e precariedade, que são os primeiros pressupostos do Realismo do século XIX. (Argan, 1992, p.52-53)

Nos estudos realizados para a tela "A Balsa da Medusa" (1819), (Fig.01), pode observar-se uma confusão de corpos entrelaçados, sofrendo a angústia do naufrágio (o tema da obra se refere a um naufrágio de uma fragata na costa africana em 1917, que teve grande repercussão da opinião pública) e desesperados, tentando o salvamento de algo que parece já estabelecido: a morte.

Nesta obra, aliás a obra mais famosa de Géricault, ele se coloca no papel de intérprete da opinião pública e porta voz da dor daqueles corpos. Heró́smo e glória versus desespero e morte estampados na catástrofe. As figuras humanas são retratadas dentro da tradição clássica da pintura histórica, mas a situação que as envolve gera um plano instável - da morte e do desespero. É o contraste entre a beleza dos corpos, (embora destroçados e desfigurados pelo acidente) versus o realismo do acontecimento. 
Na obra "Fragmentos Anatômicos" (1818), que Coli (2002) define como "figurações de partes mortas, a espera de putrefação." (Coli, 2002, p.8) e exemplifica bem o espírito dessa época, Géricault, apresenta o tema singular de pedaços de pernas e braços humanos. Partes de corpos, que o artista preferiu não identificar quem eram exatamente para demonstrar sua intenção de não reconstruí-los e sim de representá-los fragmentados, podem ser observados.

Com o Impressionismo - movimento artístico que revolucionou profundamente a Arte e sobretudo a Pintura - iniciam-se as grandes tendências da arte do século XX.

Brevemente falando, os artistas impressionistas procuraram retratar em suas pinturas as constantes alterações que a luz provoca na natureza, através da observação do efeito da luz sobre os objetos.

Quanto à figura humana, destacamos Edgar Degas (1834 - 1917), sobretudo por sua preocupação em apreender o momento do movimento ou da expressão do corpo , como nas telas "Ensaio de Bale no Palco" (1873) e "O Ensaio" (1877). Uma de suas contribuições mais significativas para a pintura moderna é a angulação oblíqua e o enquadramento das cenas, que mostram a grande influência da fotografia sobre sua obra.

Por volta de 1830, a invenção da Fotografia revela, através dos planos de composições e percepção mais detalhada de imagens, coisas que o olhar humano, mais lento e menos preciso, não conseguia captar. Surgem as discussões entre a pintura e a fotografia,

\begin{abstract}
a hipótese de que a fotografia reproduz a realidade como ela é e a pintura a reproduz como a se vê é insustentável: a objetiva fotográfica reproduz, pelo menos na primeira fase de seu desenvolvimento técnico, o funcionamento do olho humano (Argan, 1992, p.79).
\end{abstract}

O amplo registro dos movimentos, a disposição e a iluminação dos objetos, bem como os enquadramentos e os novos enfoques trazidos pela fotografia, possibilitaram ao pintor mais dinamismo, riqueza de detalhes e a desconstrução dos contornos dos objetos, face à deformação que a foto causa ao captar a velocidade do movimento de um objeto.

Segundo Rosa Olivares ${ }^{2}(1998)$ o olhar humano é o instrumento que mais fragmenta as imagens que são produzidas ao redor do próprio ser humano, e afirma ainda que

\begin{abstract}
... a arte se faz basicamente com o olhar; por isso a história da arte, a história das imagens, sagradas ou artísticas, é repleta de fragmentos de corpos. Somente a câmera fotográfica e posteriormente a imagem cinematográfica conseguiram igualar-se ao olho... (Olivares, 1998, p.508).
\end{abstract}

Em 1907, influenciado pelas pesquisas de Paul Cézanne (1839 -1906), pelos precursores do Cubismo (1908) assim como pela Arte Africana, o artista espanhol Pablo Picasso (1881-1973) pinta "Le Demoiselles d'Avignon" (1907) e realiza, segundo Argan (1992), a primeira ação de ruptura na História da Arte Moderna. Nesta obra, Picasso decompõe o fundo e as figuras humanas em inúmeros planos rígidos e agudos. A pintura representa mimeticamente o tema da Figura Humana, mas o espaço se torna multifacetado, onde figura e fundo, forma e espaço não se distinguem.

Picasso abre caminho para o Cubismo Analítico (1908) que quebra a relação espaço-forma e revela uma continuidade absoluta entre o objeto e o espaço. Segundo

\footnotetext{
2 Neste texto, traduzido do espanhol por Sandra Cowie, para o Catálogo da XXIV Bienal de São Paulo Núcleo Histórico: Antropologia e Histórias de Canibalismos (1998), Rosa Olivares trata a fragmentação como uma forma do homem-artista se relacionar com seu próprio corpo e relata diferentes processos de fragmentação em obras de artes visuais.
} 
Argan: "... a imagem parece esboçada, talhada, gravada no espaço, que se converte em matéria sólida...," (Argan, 1992, p.680) ao mesmo tempo em que penetra na superfície da pintura.

Em 1937, Picasso pinta para o pavilhão da República Espanhola na Exposição Internacional de Paris, o mural "Guernica" (1937). Este painel ${ }^{3}$ pode ser considerado um exemplo de fragmentação do tema da figura humana e nele o artista explora as distorções, fragmentações e metamorfoses que dilaceram o corpo humano em partes.

Paralelamente movimentos como o Futurismo (1910), Dadaísmo (1914) e o Surrealismo (1917) através de seus ideais e manifestos, geram novas tendências no tratamento da figura humana nas Artes Plásticas. Como o Futurismo, que defende o movimento enquanto velocidade traduzida como uma força física que deforma os corpos até o limite de sua elasticidade, revelando no efeito o dinamismo invisível da causa.

Em Marcel Duchamp (1887-1968), figura determinante para o Dadaísmo, a mudança ocorre na estrutura do objeto. Na obra "Nu descendant un escalier no. 2" (1912), Duchamp desmembra o corpo humano, multiplica seus componentes, altera o tipo morfológico de seus órgãos internos e muda o sistema do seu funcionamento biológico para uma mecânica mais condizente com a sociedade moderna.

Entre 1945 e 1950 "... a decomposição cubista permanece como a grande descoberta do século, mas deve ser explosiva e não analitica, refletir no rompimento da forma a imagem do real elaborada pela consciência dilacerada contraditória do homem do nosso tempo." (Argan, 1992, p. 534).

Com a Nova Figuração (Argan, 1992, p.559), o que fica em evidência não é a questão do reconhecimento ou não da figura do corpo. A nova imagem ressalta que ela não se resume somente neste caráter da representação da figura humana e sim no valor que se confere a ela. Sobre a Nova Imagem, uma das tendências internacional da nova pintura Bonito Oliva ${ }^{4}$ (Oliva,1982) ressalta que esta fragmentação da imagem pode ocorrer tanto no plano formal quanto no temático e se configurar num sintoma: "Trabalhar em fragmentos significa preferir as vibrações da sensibilidade ao conteúdo ideológico monolítico. Essas vibrações são necessariamente descontínuas.(...) Os fragmentos são sintomas de um êxtase de dissociação. São signos de um desejo de mutaçoes contínuas." (Oliva, 1982, p.38), ou num espírito do tempo do qual fala Omar Calabrese (1988), sobre o que trataremos mais adiante.

Nesse contexto citamos o artista inglês Francis Bacon (1909-1992) e a sua polêmica produção pictórica, que "... assinala o limite extremo da desvalorização, da degradação voluntária não apenas da figura, mas da pintura como arte da figuração." (Argan, 1992, p.559). Ainda em Argan e sobre Bacon, fica clara a intenção de desconstrução da imagem do corpo e a polêmica da Nova Figuração: “... é absurdo falar em 'nova figuração' para a deliberada e atroz desfiguração de Bacon." (Argan, 1992, p. 489), que se apropria da figura humana para deformá-la e depreciála diante do público.

Outro artista que explorou a fragmentação da figura humana foi Wandy Warhol (1930-1987), (fig.02) grande idealizador da Pop Art americana (1960), considerado um dos precursores do uso dessa temática na pintura contemporânea. Sobre seus torsos, afirma King (1996): "Ao rever as imagens de Warbol de corpo bumano, tem-se a impressão que o artista preferia focalizar as partes ou fragmentos, como as cabeças, torsos, pênis ou pés." (King, 1996, p.42).

Para o teórico italiano Omar Calabrese (1988) esse fenômeno está diretamente relacionado à perda da totalidade ou “... perda da integridade, da globalidade, da sistematicidade

\footnotetext{
3 Sobre "Guernica", afirma Argan (1992): "Com ele morre a arte, a civilização 'clássica', a arte e a civilização cuja meta era o conhecimento, a compreensão plena da natureza e da história.” (Argan, 1992, p.476)

${ }^{4}$ Bonito Oliva, crítico italiano, que criou um conjunto de formulações teóricas que embasou a produção de pintura dos anos 80 .
} 
ordenada em troca de uma instabilidade, da polidimensionalidade, da mutabilidade" (Calabrese, 1988, p.10), que se manifesta nos mais variados campos de conhecimento e da vida do homem atual.

É uma característica do espírito do nosso tempo, que Calabrese (1988) denomina de neobarroco: "O 'neobarroco' é simplesmente um 'ar do tempo' que alastra os fenômenos culturais de hoje, em todos os campos do saber ...” (Calabrese, 1988, p.10) e que, entre outras características, é marcada pelo uso de fragmentos e pormenores de imagens, esculturas e trechos de obras aplicados aos mais variados tipos de textos - visuais ou literários.

Esse modo, esse ar do tempo, pode ser observado na constante presença de obraspormenor e obras-fragmento que muitos artistas contemporâneos produzem. "... pormenor e fragmento, embora tão diferentes entre si, acabam por participar do mesmo 'espirito do tempo', a perda da totalidade." (Calabrese, 1988, p. 103).

Para deixar claro o que consideraremos pormenor e fragmento nesta pesquisa é fundamental relatar, embora brevemente, alguns pontos sobre estes conceitos, tendo como suporte o capítulo IV - "Pormenor e Fragmento" do livro A Idade Neobarroca (1988) de Omar Calabrese.

Primeiramente devemos considerar a idéia do "todo", "sistema" e "conjunto", que pressupõe a "parte", "porção", "fragmento" e o "pormenor" (Calabrese, 1988, p.83). Portanto a primeira consideração: o fragmento e o pormenor são sinônimos de parte, são termos interdefinidos, porém conceitos em oposição, já que são duas ações efetivas concebidas de maneira completamente diferentes ${ }^{5}$.

A palavra pormenor, ou detalhe, tem origem no francês renascentista e significa "talhar-se" (Calabrese, 1988, p.85). Esse talhar-se nos remete a uma ação do sujeito sobre ele mesmo. O pormenor só pode ser observado a partir do inteiro e da operação do talho. Um exemplo comum dessa ação é o zoom da televisão.

Já o fragmento, e Calabrese frisa isso no seu texto, elabora sua ação - de tornar-se parte, de uma maneira completamente diferente. O fragmento quebra, corta-se e se separa totalmente do conjunto e ao cindir sua relação com o todo, se torna autônomo. A etimologia do fragmento deriva do latim "frangere" que significa "quebrar" (Calabrese, 1988, p.87). E essa é sua diferença basal para com o pormenor. $O$ fragmento não contempla um inteiro anterior a ele para ser definido. Ele será observado tal como ele é e não como uma ação de um sujeito anterior. Há uma ruptura com o sistema que o gerou, enquanto que o pormenor dialoga constantemente com o conjunto que o gerou.

Para Calabrese (1988) pode acontecer de um fragmento se tornar ele mesmo o próprio sistema:

Isto é, quando se apresenta uma obra fragmentária de aspecto verdadeiramente inteiro. Neste caso, falta sua referência, e o 'fragmento' nada pressupõe fora dele, remete para a sua pura fenomenologia (Calabrese, 1988, p.89).

Portanto, a presente pesquisa pretende analisar crítica e comparativamente, um conjunto de pinturas cuja temática é a Figura Humana Fragmentada - representada por partes - a fim de classificá-las como obras-fragmento, contextualizá-las e identificá-las como obras resultantes do espírito do tempo contemporâneo, logo, participantes do estilo neobarroco, onde o fragmento possue mesmo valor que o todo e a parte de um corpo tem tanta importância quanto o corpo intacto.

\footnotetext{
5 Omar Calabrese afirma ainda: "termos que mantêm relações de reciprocidade, implicação e pressuposição". Para Calabrese: "Um não se explica sem o outro”. (Calabrese, 1988, p. 83-104)
} 


\section{Referências Bibliográficas:}

ARGAN, Giulio C. Arte Moderna: do Iluminismo aos movimentos contemporâneos. Trad. Denise Bottman e Frederico Carott. São Paulo: Companhia das Letras. 1992.

CALABRESE, Omar. A Idade Neobarroca. São Paulo: Martins Fontes. 1988. - A Linguagem da Arte. Rio de Janeiro: Ed. Globo. 1987.

CANTON, K. Arte Contemporânea e Corpo Virtual. Em LEÃO, L. (org.),

INTERLAB,São Paulo, Ed. Iluminuras Ltda, 2002.

COLI, Jorge. O Fascínio de Frank Einstein. Folha de São Paulo. São Paulo, 02/06/2002. Caderno Mais! No. 538, p. 4-11.

KING, Margery. Rostos Conhecidos, Órgãos Genitais, os Retratos e Torsos de Andy Warhol. Em FUNDAÇÃO BIENAL DE SÃO PAULO. Catálogo $23^{a}$ Bienal Internacional de São Paulo: Salas Especiais. São Paulo. 1996. vol.01, p. 40-53.

OLIVA, Achille B. The Internacional Trans - Avantgarde. Flash Arte, n.104, out/nov, 1981, p.38.

OLIVARES, Rosa (1998). Pedaços de Nós Mesmos. Em FUNDAÇÃO BIENAL DE SÃO PAULO. Catálogo 24 Bienal de São Paulo: Núcleo Histórico - antropofagia e histórias de canibalismos, São Paulo, vol. 01, 1998, p. 508-512.

atual . Em GRANDO, J.C. A (Des) Construção do Corpo. Blumenau: Edifurb, 2001.

VILLAÇA, N. e GÓES, F. A Emancipação cultural do corpo .Em VILLAÇA, N. e

GÓES, F. (org.) Nas Fronteiras do Contemporâneo : território, identidade, arte, moda, corpo e mídia. Rio de Janeiro: Ed. Mauad/ FUJB, 2001.

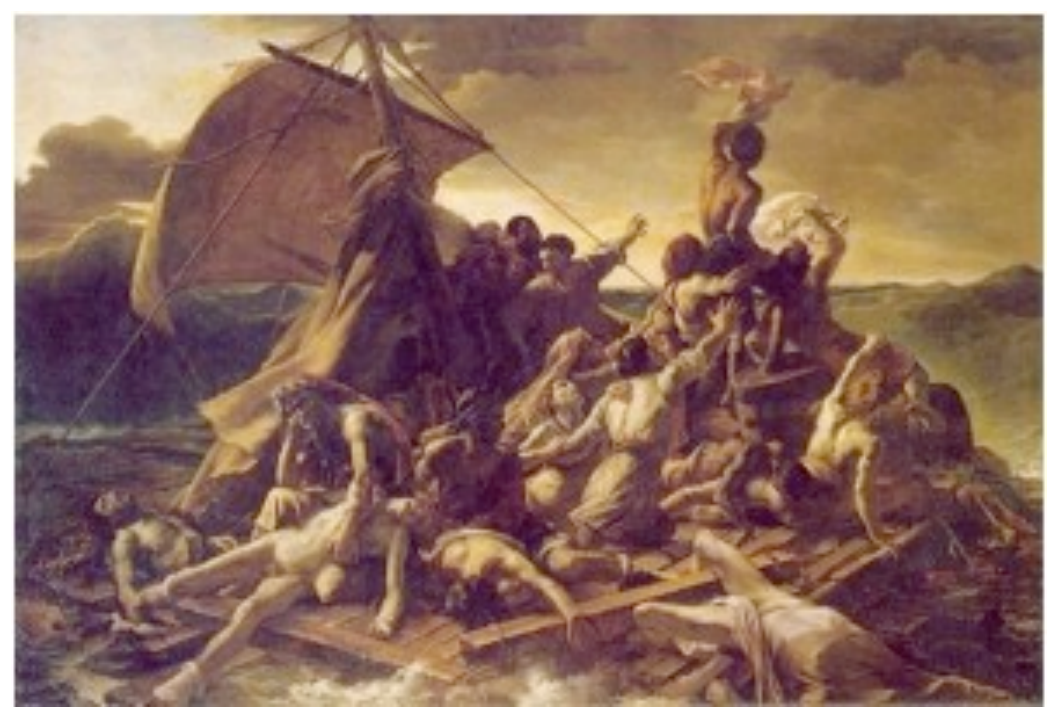

Figura 01

Theodore Géricault

"A Balsa da Medusa"

(1893) 


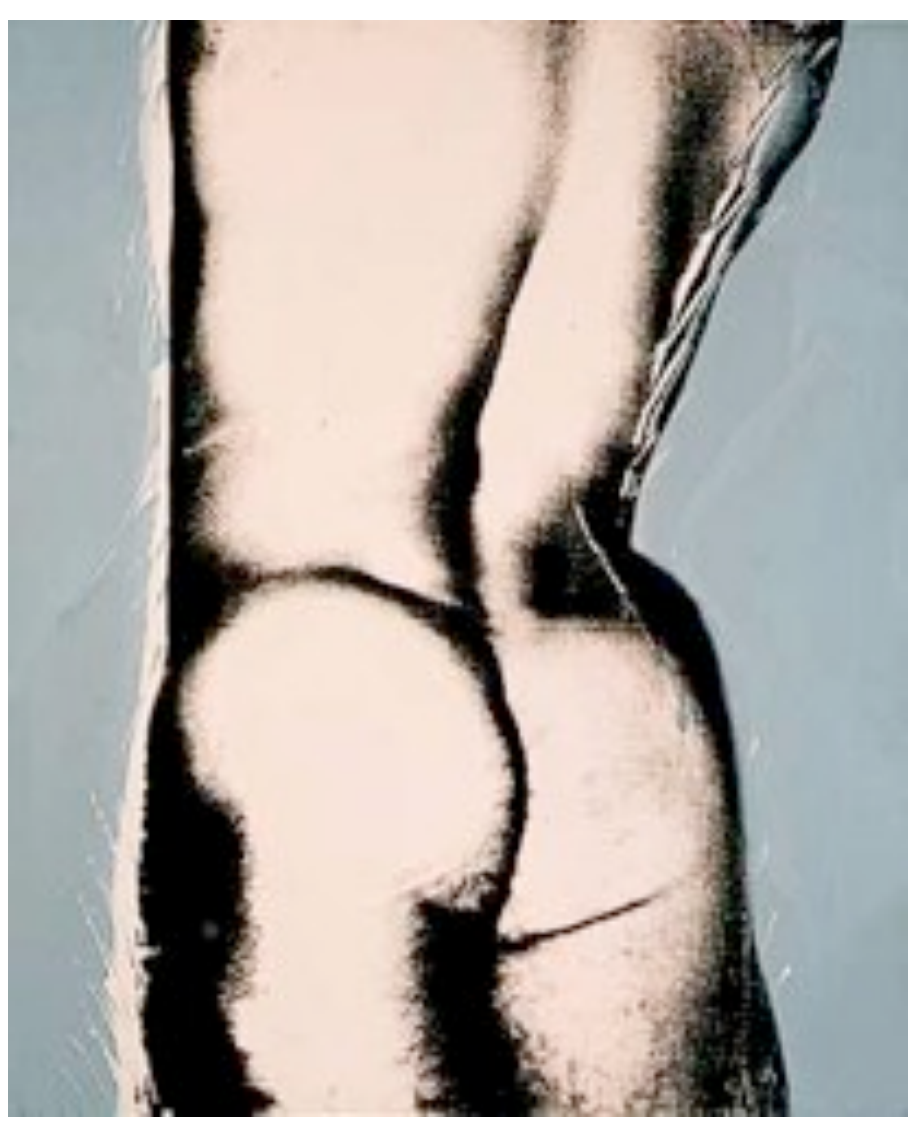

Figura 02 Andy Warhol "Torso masculino" (1977) 